\title{
Discrete Element Modeling on Mechanical Behavior of Heterogeneous Rock Containing X-Shaped Fissure under Uniaxial Compression
}

\author{
Ming Chen $\mathbb{D}^{1,2}$ Jian Liu, ${ }^{1,2}$ Zhengyong Xie, ${ }^{3}$ Jianjun Liu, ${ }^{1,2}$ Xunjian Hu, ${ }^{1,2}$ Bingyang Li, ${ }^{1,2}$ \\ and Yue $\operatorname{Cen}^{1,2}$ \\ ${ }^{1}$ State Key Laboratory of Geomechanics and Geotechnical Engineering, Institute of Rock and Soil Mechanics, Chinese Academy \\ of Sciences, Wuhan 430071, China \\ ${ }^{2}$ University of Chinese Academy of Sciences, Beijing 100049, China \\ ${ }^{3}$ Hubei Road and Bridge Group Tianxia Construction Co. Ltd., Wuhan 430000, China
}

Correspondence should be addressed to Ming Chen; 2273931596@qq.com

Received 1 September 2020; Revised 22 September 2020; Accepted 23 September 2020; Published 17 October 2020

Academic Editor: Yanlin Zhao

Copyright (c) 2020 Ming Chen et al. This is an open access article distributed under the Creative Commons Attribution License, which permits unrestricted use, distribution, and reproduction in any medium, provided the original work is properly cited.

\begin{abstract}
Based on the experimental results of an intact rock specimen under uniaxial compression, particle flow code $\left(\mathrm{PFC}^{2 \mathrm{D}}\right) \mathrm{was}$ adopted to carry out a discrete element modeling (DEM) for the mechanical behavior of heterogeneous rocks containing X-shaped fissures (two intersecting symmetric single fissures) under uniaxial compression. The influences of $\beta$ (the acute angle between two single fissures) and the direction angle $\alpha$ (the acute angle between the bisector of $\beta$ and perpendicular to the loading direction) on the strength, deformation, energy, crack propagation, and ultimate failure mode were analyzed in detail. Numerical simulated results showed the following: (1) Due to the X-shaped fissures, not only the peak strength, elastic modulus, crack initiation stress, and damage stress were significantly reduced, and the reduced degree of the peak strength was obviously greater than that of the elastic modulus, but also the brittleness and energy were significantly weakened. (2) The peak strength and elastic modulus generally decreased with the increase of $\beta$ and increased with the increase of $\alpha$. Moreover, the change trends of crack initiation stress, damage stress, boundary energy, and total strain energy at the peak stress were consistent with the peak strength. (3) Regardless of the changes of $\alpha$ and $\beta$, models all firstly initiated wing cracks at the two tips of the single fissure with a larger inclination angle, and the crack initiation angle decreased with the increase of the inclination angle of the single fissure. (4) The fracture was dominated by tensile microcracks, and no microcracks were generated in a certain range of the X-shaped fissure center. The failure mode was mainly split along the axial direction, and the failure surface started from the tips of the fissure and extended to both ends of models. (5) The uniaxial compressive strength and elastic modulus increased exponentially with the increase of the homogeneity factor. When the homogeneity factor was small, the microcracks were more evenly distributed in the models; when the homogeneity factor was large, the microcracks were mainly concentrated at the tips of the fissure in the models. This study can provide some references for the correct understanding of the mechanical properties of rock masses containing X-shaped fissures.
\end{abstract}

\section{Introduction}

Due to the long-term geological tectonics and human activities, there are often many natural fissures in the rock mass, which will degrade the mechanical properties of rock mass [1-12] and lead to engineering accidents and disasters. Therefore, the research on the mechanical behavior of fissured rocks has always been the focus of the geotechnical engineering community.

At present, many scholars at home and abroad have studied the influence of the shape, size, number, and distribution characteristics of the fissures on the mechanical properties, crack propagation, and failure modes of the rock through experiments and numerical simulations [6, 13-25]. For 
example, Wang YX et al. [13] have carried out uniaxial compression experiments on the granite specimens with a central hole and hole edge flaws, and the results showed that the mechanical parameters and crack types of the specimens distinctly vary with the flaw inclination. Wang CL et al. [15] have studied the propagation of collinear cracks and cracking processes under uniaxial compression by experiment and numerical simulation. Liu XR et al. [16] have studied the failure behavior and fracture mechanism of sandstone containing elliptical holes and fissures through experiments, and the results showed that the ligament angle has a significant impact on rock strength and deformation. Wu JY et al. [17] have studied the length of preexisting fissures effects on the strength and deformation of red sandstone through experiments, and the results showed that as the fissure length increases, the strength and deformation parameters decrease in a negative exponential manner. Dong QQ et al. [18] and Ma GW et al. [19] have shown that the inclination angle and effective curvature of the S-shaped fissure have a great influence on the crack propagation and failure mode of the specimen through experiments and numerical simulations. Yang SQ et al. [20] have conducted experiments and numerical simulations on red sandstone containing a single nonstraight fissure, and the results indicated that as the inclination angle increases, the peak strength, peak strain, and elastic modulus increase as a whole. Moreover, when the inclination angle is smaller or larger, the crack first initiated from the convex point of the prefabricated fissure; when the inclination angle is intermediate, the crack initiation position transferred from the convex point to the tip of the prefabricated fissure. Yang SQ et al. [21] have showed that the oval flaw angle has an effect on the macroscopic strength parameters and crack modes of sandstone through experiments and numerical simulation. Chen LY et al. [22] have analyzed the influence of fissure dips and rock bridge dips on strength, crack propagation, and evolution laws through numerical simulation. Yang SQ et al. [23] have studied the fracture coalescence behavior of red sandstone containing two nonparallel fissures by $\mathrm{PFC}^{2 \mathrm{D}}$, and the results showed that as the fissure angle increases, the peak strength and elastic modulus first increase and then decrease. Wang GL et al. [25] have analyzed the influence of the inclination angle of the Z-shaped fissure on the strength, deformation, and crack propagation, and the results indicated that the failure modes are mainly divided into tension failure, shear failure, and tensile-shear mixed failure.

It can be seen from the above research that the current research mainly focuses on single fissures, double fissures, elliptical fissures, arc-shaped fissures, and Z-shaped fissures. However, the forms of fissures are complex and changeable, and $\mathrm{X}$-shaped fissures are also one of the widely existing fissure forms in actual rock mass engineering, as shown in Figure 1. In addition, there are currently few studies on rocks containing X-shaped fissures. There are the following problems in the experiment: (1) It is extremely difficult to prepare a rock sample, especially hard rock. (2) The heterogeneity of the rock leads to large dispersion of experimental results. (3) It is not easy to directly observe the crack propagation inside the rock. However, numerical simulation can solve the above

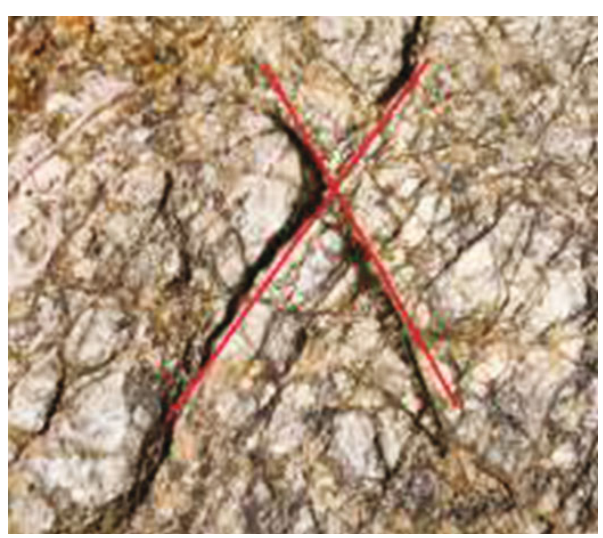

FIGURE 1: The X-shaped fissures in rock mass.

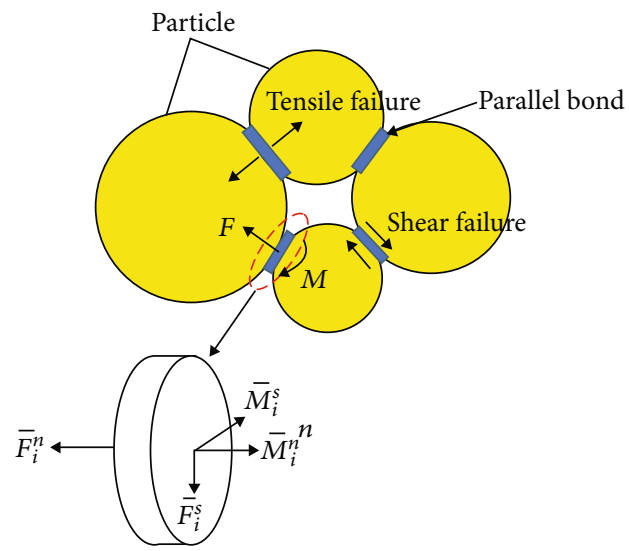

Figure 2: Mechanical mechanism of parallel bond model [28].

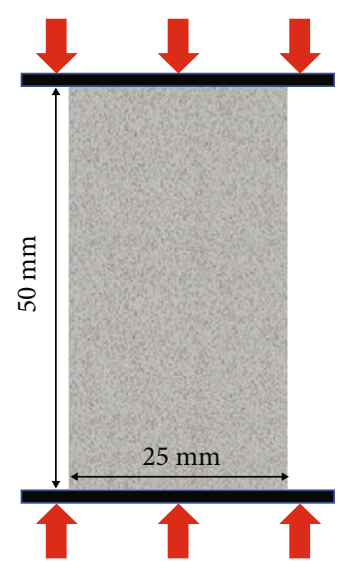

FIGURE 3: Intact numerical model generated in $\mathrm{PFC}^{2 \mathrm{D}}$ in this research.

problems. In view of this, this paper intended to use particle flow code $\left(\mathrm{PFC}^{2 \mathrm{D}}\right)$ [26] to carry out the numerical simulation for the mechanical behavior and failure characteristics of heterogeneous rock specimens containing $\mathrm{X}$-shaped fissures under uniaxial compression. This study can provide some references for the correct understanding of the mechanical properties of rock masses containing X-shaped fissures. 


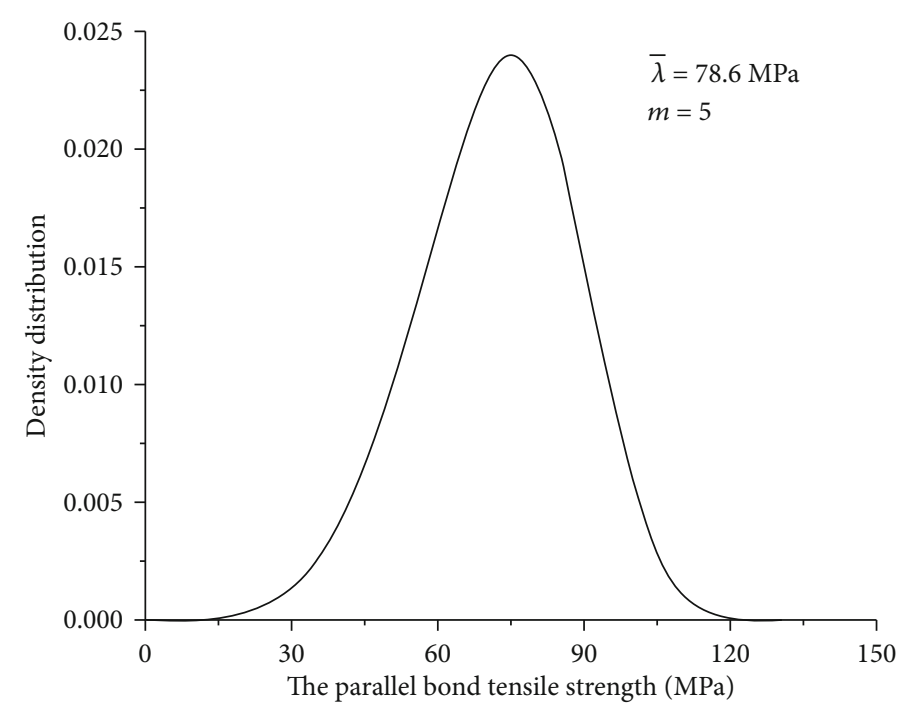

FIgURE 4: The density distribution of the parallel bond tensile strength $(\bar{\lambda}=78.6 \mathrm{MPa}, m=5)$.

TABle 1: The microparameters used in the $\mathrm{PFC}^{2 \mathrm{D}}$ model.

\begin{tabular}{lc}
\hline Microparameters & Values \\
\hline Particle density $\left(\mathrm{kg} \cdot \mathrm{m}^{-3}\right)$ & 2560 \\
Minimum particle size $(\mathrm{mm})$ & 0.11 \\
Particle size ratio & 1.66 \\
Particle contact modulus $(\mathrm{GPa})$ & 14 \\
Particle stiffness ratio & 3.0 \\
Particle friction coefficient & 1.2 \\
Homogeneity factor & 5 \\
Parallel bonding modulus $(\mathrm{GPa})$ & 14 \\
Parallel bonding stiffness ratio & 3.0 \\
Characteristic value of parallel bond tensile strength $(\mathrm{MPa})$ & 78.6 \\
Characteristic value of parallel bond cohesion $(\mathrm{MPa})$ & 138.6 \\
Friction angle of parallel bond $\left(^{\circ}\right)$ & 30.0 \\
\hline
\end{tabular}

\section{Discrete Element Modeling Method}

2.1. Particle Flow Code (PFC $\left.{ }^{2 D}\right)$. Based on the discrete element method, Cundall and Strack [27] established the particle flow theory in 1979, and later, the United States Itasca company developed the particle flow program commercial software PFC. In this research, we chose the parallel bond model (PBM) to carry out the numerical simulation, as shown in Figure 2 [28]. The particles are cemented together by parallel bonds, so the relative motion between the particles will cause a force and a moment to develop within the bond material, and this force and moment act on the two bonded particles. The forces and moments can be decomposed into $\bar{F}_{i}^{n}$ and $\bar{M}_{i}^{n}$ along the normal direction and $\bar{F}_{i}^{s}$ and $\bar{M}_{i}^{s}$ along the tangential direction. When the normal stress generated in the parallel bond is greater than the normal strength of the bond material, the tensile failure of the parallel bond generates a tensile crack; when the tangential stress generated in the parallel bond is greater than the shear strength of the bond material, the shear failure of the parallel bond generates a shear crack.
2.2. Calibrating Microparameters by Experimental Results of Intact Specimen. The intact specimens were taken from the tuff in the volcanic reservoir of the Xushen Gas Field in the experiment. First, the intact specimens were processed into a cylindrical standard specimen with a diameter of $25 \mathrm{~mm}$ and height of $50 \mathrm{~mm}$ and then were loaded with a displacement control method at a rate of $0.005 \mathrm{~mm} / \mathrm{s}$.

Figure 3 showed one intact numerical model generated by $\mathrm{PFC}^{2 \mathrm{D}}$, and the scale of the numerical model was similarly equal to that of the experimental specimen, i.e., the dimensions of $25 \mathrm{~mm}$ in width and $50 \mathrm{~mm}$ in height. Each intact numerical model was discretized into 16542 particles and 39379 parallel bonded contacts. By giving the upper and lower walls a certain speed, quasistatic loading was achieved for simulating uniaxial compression experiments.

Due to the differences in the size, shape, mineral types of the rock-forming mineral particles, and diagenesis in the rock, its mechanical properties showed great heterogeneity. Many scholars had adopted the Weibull distribution to characterize the heterogeneity of mechanical parameters in 
TABLE 2: Comparison between experimental and numerical mechanical parameters of the intact specimen.

\begin{tabular}{lccc}
\hline & $\begin{array}{c}\text { Peak strength } \\
(\mathrm{MPa})\end{array}$ & $\begin{array}{c}\text { Elastic modulus } \\
(\mathrm{GPa})\end{array}$ & $\begin{array}{c}\text { Poisson's } \\
\text { ratio }\end{array}$ \\
\hline $\begin{array}{l}\text { Numerical } \\
\text { results }\end{array}$ & 183.0 & 20.49 & 0.26 \\
$\begin{array}{l}\text { Experimental } \\
\text { results }\end{array}$ & 176.7 & 20.66 & 0.25 \\
Relative error & $3.57 \%$ & $0.82 \%$ & $4.00 \%$ \\
\hline
\end{tabular}

numerical simulations $[29,30]$. Therefore, this paper set the values of the parallel bond tensile strength and parallel bond cohesion in the particle flow model to obey the Weibull distribution, and the probability density function of $f(\lambda)$ is

$$
f(\lambda)=\frac{m}{\bar{\lambda}}\left(\frac{\lambda}{\bar{\lambda}}\right)^{m-1} e^{-(\lambda / \bar{\lambda})^{m}}, \quad \lambda \geq 0
$$

where $m$ is the homogeneity factor (the smaller the value of $m$ , the greater the heterogeneity of the model), $\lambda$ is the parallel bond tensile strength and parallel bond cohesion, and $\bar{\lambda}$ is the characteristic value of parallel bond tensile strength and parallel bond cohesion. For example, Figure 4 shows the density distribution of the parallel bond tensile strength, with the values of $\bar{\lambda}$ and $m$ being $78.6 \mathrm{MPa}$ and 5 , respectively.

During the calibration process, microparameters were confirmed by using the trial and error method. The macroscopic behavior (i.e., the peak strength, elastic modulus, Poisson's ratio, the stress-strain curve, and the failure mode) of an intact specimen obtained by experiment was used in this research to calibrate the microparameters. The macroscopic results obtained by numerical simulation after each trial were used to check the microparameters. This process was repeated until the numerical results achieved a good agreement with the experimental results. Table 1 lists the microparameters used in the $\mathrm{PFC}^{2 \mathrm{D}}$ model in this research. Table 2 shows the comparison between experimental and numerical mechanical parameters of the intact specimen. In accordance with Table 2, we can conclude that the relative error of mechanical parameters was very small between numerical results and experimental results. Besides, Figure 5 shows the comparison between experimental and numerical stress-strain curves and failure mode of the intact specimen under uniaxial compression. From Figure 5, it can be seen that the stress-strain curve and the failure mode were well in an agreement between numerical results and experimental results. The comparisons shown in Table 2 and Figure 5 calibrated the rightness and reasonability of microparameters used in Table 1. Later, it can be used for the simulation of the numerical models containing $\mathrm{X}$-shaped fissure.

\subsection{Establishment of Numerical Models Containing X-Shaped} Fissure. After generating the intact numerical model, we created open $\mathrm{X}$-shaped fissures by deleting particles [23]. The layout of the X-shaped fissure is shown in Figure 6. The intersection point of fissure (1) and fissure (2) was located in the center of the model. The length and width of fissure (1) and

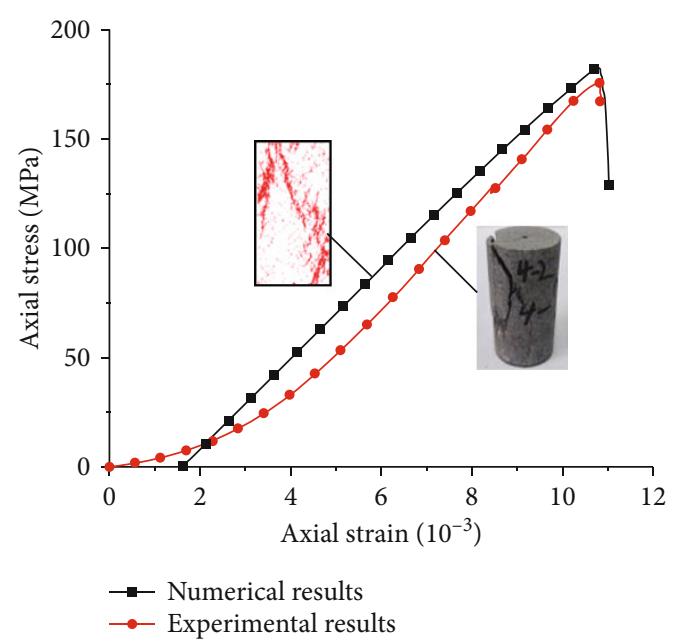

FIgURe 5: Comparison between experimental and numerical stressstrain curves and failure mode of the intact specimen.

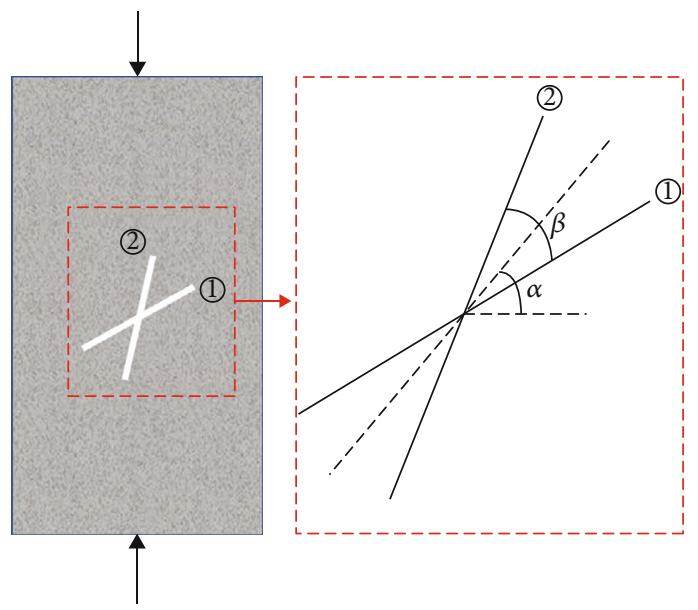

Figure 6: The layout of X-shaped fissure.

fissure (2) were both $10 \mathrm{~mm}$ and $0.5 \mathrm{~mm}$, respectively. $\beta$ was the acute angle between fissure (1) and fissure (2), and $\alpha$ was the acute angle between bisector of $\beta$ and perpendicular to the loading direction. In order to investigate in detail the influence of $\alpha$ and $\beta$ on the mechanical behavior of rock containing $\mathrm{X}$-shaped fissure, we designed the following two simulation schemes: (1) $\alpha$ was constant at $45^{\circ}$, and $\beta$ was $15^{\circ}, 30^{\circ}$, $45^{\circ}, 60^{\circ}, 75^{\circ}$, and $90^{\circ}$, respectively, and (2) $\beta$ was constant at $60^{\circ}$, and $\alpha$ was $0^{\circ}, 15^{\circ}, 30^{\circ}, 45^{\circ}, 60^{\circ}, 75^{\circ}$, and $90^{\circ}$, respectively.

\section{Simulation Results}

3.1. Strength and Deformation Characteristics. When stress drops to $70 \%$ of the peak stress, the calculation was stopped in the numerical simulation in this research. From the stress-strain curve in Figure 7, the following can be seen: (1) The stress-strain relationship of the intact numerical model and the models containing X-shaped fissure was both nearly linear. Before the peak stress, it was mainly manifested as elastic deformation, with little plastic deformation. After 


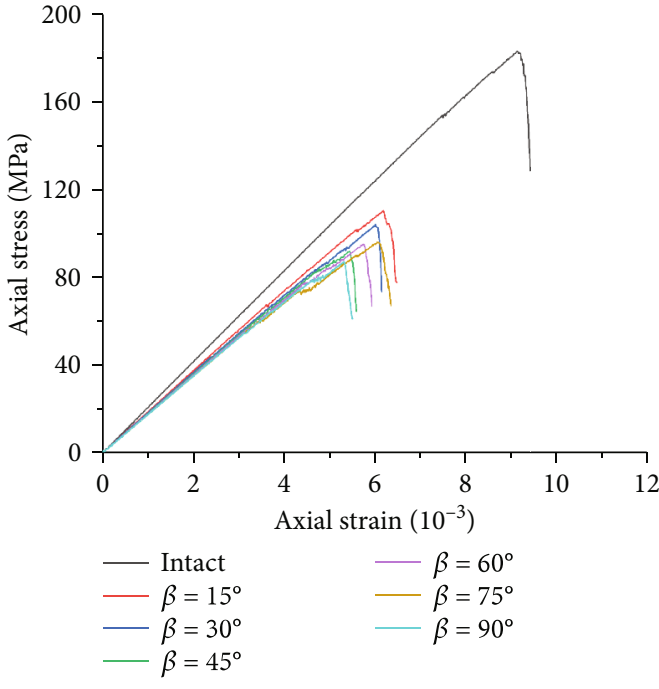

(a) $\alpha=45^{\circ}$

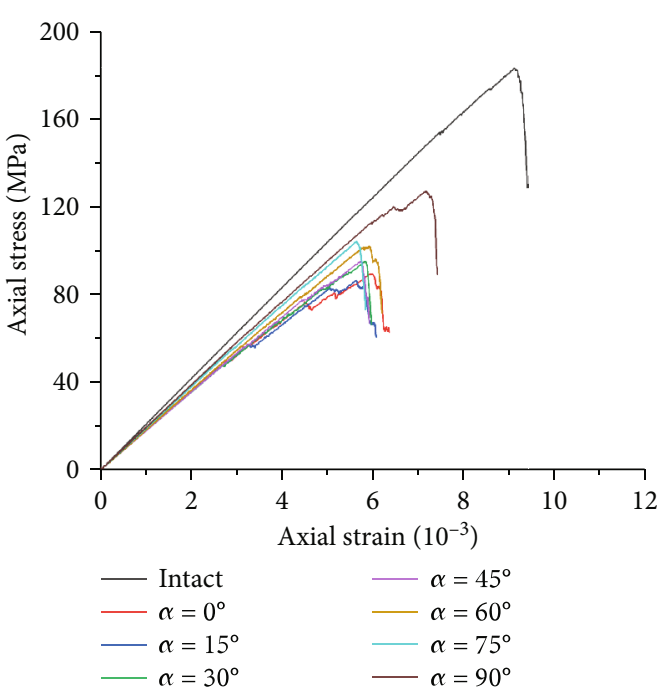

(b) $\beta=60^{\circ}$

FIGURE 7: Stress-strain curves of numerical models.

the peak stress, the stress dropped rapidly, showing that the tuff had typical brittle failure characteristics. (2) Compared with the intact numerical model, the elastic stage of numerical models containing X-shaped fissure was significantly shorter, and parts of specimens had obvious stress drops before the peak stress, which was due to local damage caused by new or existing crack propagation and penetration. (3) Compared with the intact numerical model, the numerical models containing X-shaped fissure had a smaller stress drop rate after the peak stress, indicating that the $\mathrm{X}$-shaped fissure weakened the brittleness of the rock and increased the ductility. The above conclusions were consistent with the numerical simulation results of other scholars [25].

The peak strength and elastic modulus obtained from the stress-strain curves in Figure 6 are shown in Table 3. It can be seen that compared with the intact numerical model, the peak strength and elastic modulus of the numerical models containing X-shaped fissure were significantly reduced, indicating that the $\mathrm{X}$-shaped fissure has greatly degraded the mechanical properties of rock. The damage coefficient of $\eta$ was used to quantitatively describe the degree of deterioration, which is determined by the following formula [1]:

$$
\eta=\frac{\delta_{1}-\delta_{2}}{\delta_{1}}
$$

where $\delta_{1}$ and $\delta_{2}$ are the mechanical parameters of the intact numerical model and the models containing $\mathrm{X}$-shaped fissure, respectively. The damage coefficient calculated by the above formula is shown in Table 3. The following can be seen: (1) The peak strength damage coefficient of numerical models containing X-shaped fissure was between 0.31 and 0.53 , and the elastic modulus damage coefficient was between 0.08 and 0.21 . The peak strength damage coefficient was about 3 times the elastic modulus damage coefficient. It means that compared with the intact numerical model, the $\mathrm{X}$-shaped fissure had a greater degree of deterioration to
TABLE 3: Mechanical parameters of numerical models.

\begin{tabular}{lccccc}
\hline $\begin{array}{l}\alpha \\
\left(^{\circ}\right)\end{array}$ & $\begin{array}{c}\beta \\
\left.{ }^{\circ}\right)\end{array}$ & $\begin{array}{c}\text { Peak } \\
\text { strength } \\
(\mathrm{MPa})\end{array}$ & $\begin{array}{c}\text { Elastic } \\
\text { modulus } \\
(\mathrm{GPa})\end{array}$ & $\begin{array}{c}\text { Peak strength } \\
\text { damage } \\
\text { coefficient }\end{array}$ & $\begin{array}{c}\text { Elastic modulus } \\
\text { damage } \\
\text { coefficient }\end{array}$ \\
\hline Intact & 183.00 & 20.49 & - & - \\
45 & 15 & 110.28 & 17.73 & 0.40 & 0.13 \\
45 & 30 & 104.00 & 17.94 & 0.43 & 0.12 \\
45 & 45 & 91.90 & 17.49 & 0.50 & 0.15 \\
45 & 60 & 95.08 & 17.02 & 0.48 & 0.17 \\
45 & 75 & 96.06 & 17.54 & 0.48 & 0.14 \\
45 & 90 & 87.17 & 16.78 & 0.52 & 0.18 \\
0 & 60 & 89.48 & 16.22 & 0.51 & 0.21 \\
15 & 60 & 86.35 & 16.83 & 0.53 & 0.18 \\
30 & 60 & 95.03 & 16.99 & 0.48 & 0.17 \\
45 & 60 & 95.08 & 17.02 & 0.48 & 0.17 \\
60 & 60 & 101.95 & 17.92 & 0.44 & 0.13 \\
75 & 60 & 104.13 & 18.78 & 0.43 & 0.08 \\
90 & 60 & 126.95 & 18.84 & 0.31 & 0.08 \\
\hline
\end{tabular}

the peak strength, which was much greater than that to the elastic modulus. This conclusion was consistent with the experimental and numerical simulation results of other scholars [14]. (2) The peak strength and elastic modulus damage coefficients caused by $\alpha$ were between $0.31 \sim 0.53$ and $0.08 \sim 0.21$, respectively, while the peak strength and elastic modulus damage coefficients caused by $\beta$ were between $0.40 \sim 0.52$ and $0.12 \sim 0.18$, respectively. Among them, the damage coefficient of the former had a larger variation range than the latter, indicating that $\alpha$ had a greater influence on mechanical parameters than $\beta$.

Figure 8 shows the curves of mechanical parameters changing with $\alpha$ and $\beta$. The following can be seen: (1) With the changes of $\alpha$ and $\beta$, the peak strength changed greatly, while the elastic modulus changed less. This was because 


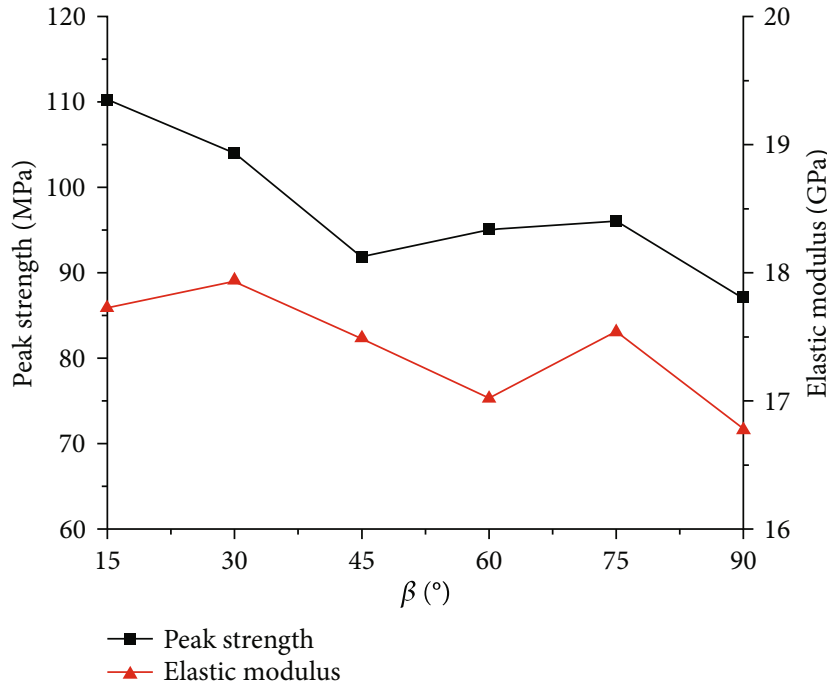

(a) $\alpha=45^{\circ}$

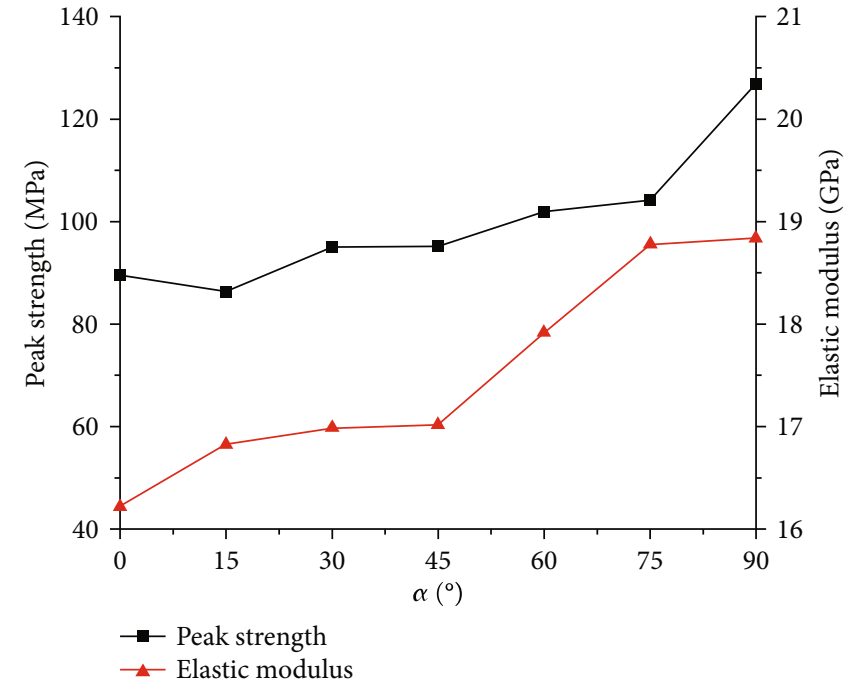

(b) $\beta=60^{\circ}$

FIGURE 8: Change curves of mechanical parameter of numerical models.

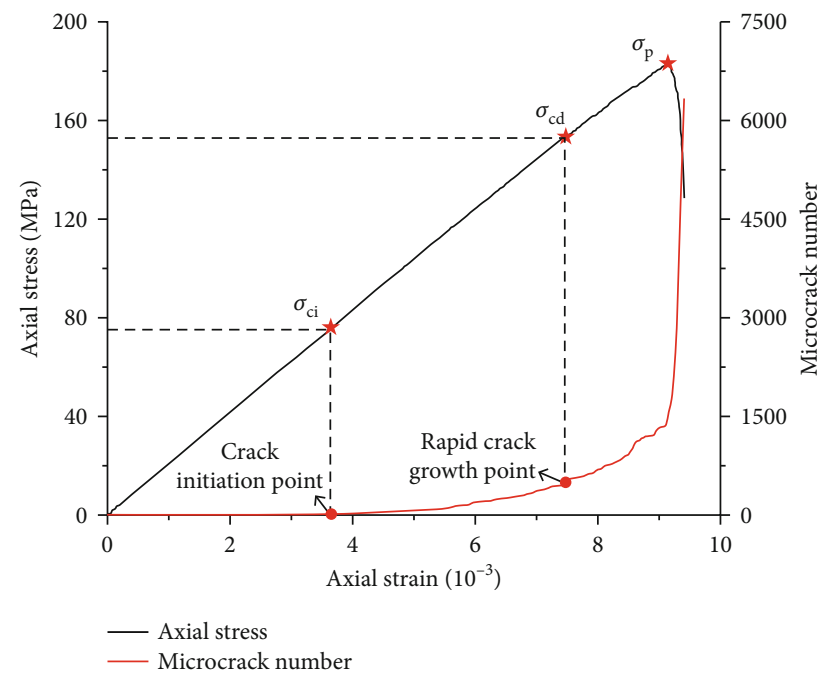

FIgURE 9: Change curve of the microcrack number in intact numerical model.

the elastic modulus was mainly related to the number of fissures; the more the number of fissures, the smaller the elastic modulus [1]. In this paper, the number of fissures was fixed, so the change of elastic modulus was small. (2) With the increase of $\beta$, the peak strength and elastic modulus showed a decreasing trend as a whole. Specifically, the peak strength first decreased, then increased and then decreased. When $\beta$ $=15^{\circ}$ and $\beta=30^{\circ}$, the peak strength was larger, which was equal to $110.28 \mathrm{MPa}$ and $104.00 \mathrm{MPa}$, respectively; when $\beta$ $=45^{\circ}$ and $\beta=90^{\circ}$, the peak strength was smaller, which was equal to $91.90 \mathrm{MPa}$ and $87.17 \mathrm{MPa}$, respectively. However, the elastic modulus first increased, then decreased, then increased, and finally decreased. The elastic modulus reached the maximum value of $17.94 \mathrm{GPa}$ at $\alpha=30^{\circ}$, while the elastic modulus reached the minimum value of $16.78 \mathrm{GPa}$ at $\alpha=90^{\circ}$.
TABLE 4: The crack initiation stress and damage stress of numerical models.

\begin{tabular}{lcccccc}
\hline$\alpha\left(^{\circ}\right)$ & $\beta\left(^{\circ}\right)$ & $\sigma_{c i}(\mathrm{MPa})$ & $\sigma_{c d}(\mathrm{MPa})$ & $\sigma_{p}(\mathrm{MPa})$ & $\sigma_{c i} / \sigma_{p}$ & $\sigma_{c d} / \sigma_{p}$ \\
\hline Intact & & 74.2 & 153.8 & 183.0 & 0.41 & 0.84 \\
45 & 15 & 44.5 & 90.3 & 110.3 & 0.40 & 0.82 \\
45 & 30 & 43.0 & 82.7 & 104.0 & 0.41 & 0.80 \\
45 & 45 & 36.8 & 74.4 & 91.9 & 0.40 & 0.81 \\
45 & 60 & 45.7 & 76.5 & 95.1 & 0.48 & 0.80 \\
45 & 75 & 44.0 & 73.4 & 96.1 & 0.46 & 0.76 \\
45 & 90 & 43.8 & 70.8 & 87.2 & 0.50 & 0.81 \\
0 & 60 & 37.5 & 74.4 & 89.5 & 0.42 & 0.83 \\
15 & 60 & 34.7 & 71.3 & 86.4 & 0.40 & 0.83 \\
30 & 60 & 34.1 & 79.5 & 95.0 & 0.36 & 0.84 \\
45 & 60 & 45.7 & 76.5 & 95.1 & 0.48 & 0.80 \\
60 & 60 & 49.3 & 83.6 & 102.0 & 0.48 & 0.82 \\
75 & 60 & 43.4 & 84.2 & 104.1 & 0.42 & 0.81 \\
90 & 60 & 55.2 & 102.5 & 127.0 & 0.44 & 0.81 \\
\hline
\end{tabular}

(3) With the increase of $\alpha$, the peak strength and elastic modulus tended to increase as a whole. Specifically, the peak strength increased slowly at $\alpha=0^{\circ} \sim 75^{\circ}$ and increased rapidly at $\alpha=75^{\circ} \sim 90^{\circ}$. The peak strength reached the maximum value of $126.95 \mathrm{MPa}$ at $\alpha=90^{\circ}$, while the peak strength reached the minimum value of $86.35 \mathrm{MPa}$ at $\alpha=$ $15^{\circ}$. However, the elastic modulus growed in an S-shaped curve. The growth was gentle at $\alpha=0^{\circ} \sim 45^{\circ}$ and $\alpha=75^{\circ} \sim$ $90^{\circ}$ and rapid at $\alpha=45^{\circ} \sim 75^{\circ}$. When $\alpha=90^{\circ}$, the elastic modulus reached the maximum value of $18.84 \mathrm{GPa}$. When $\alpha=0^{\circ}$ and $\alpha=15^{\circ}$, the elastic modulus was smaller, which was equal to $16.22 \mathrm{GPa}$ and $16.83 \mathrm{GPa}$, respectively.

In summary, the peak strength and elastic modulus decreased with the increase of $\beta$ and increased with the increase of $\alpha$ on the whole. The reason was that as $\beta$ 


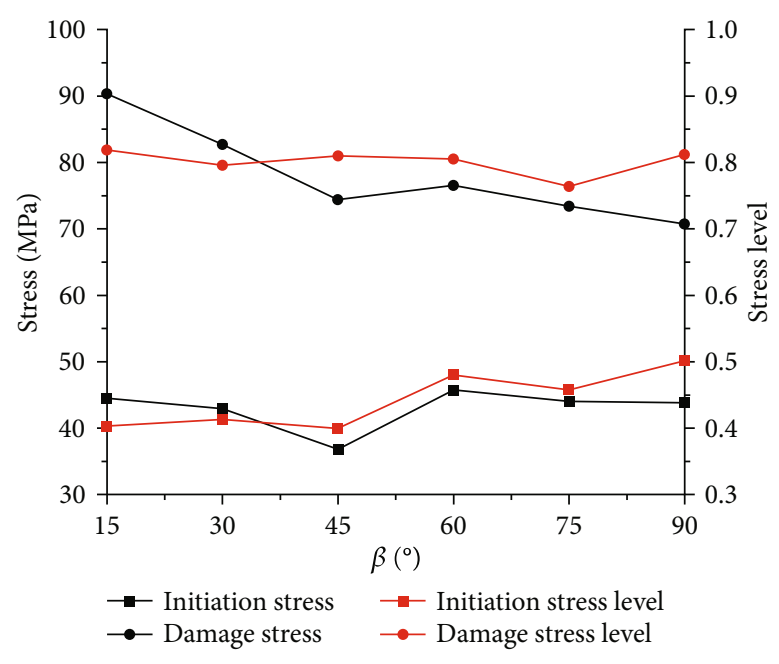

(a) $\alpha=45^{\circ}$

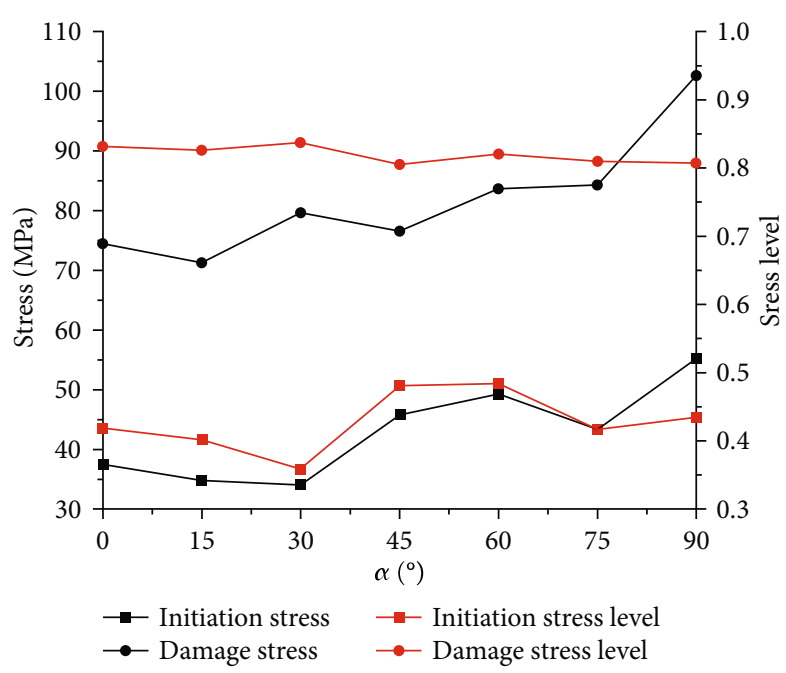

(b) $\beta=60^{\circ}$

FIGURE 10: Change curves of crack initiation stress and damage stress of numerical models containing X-shaped fissure.

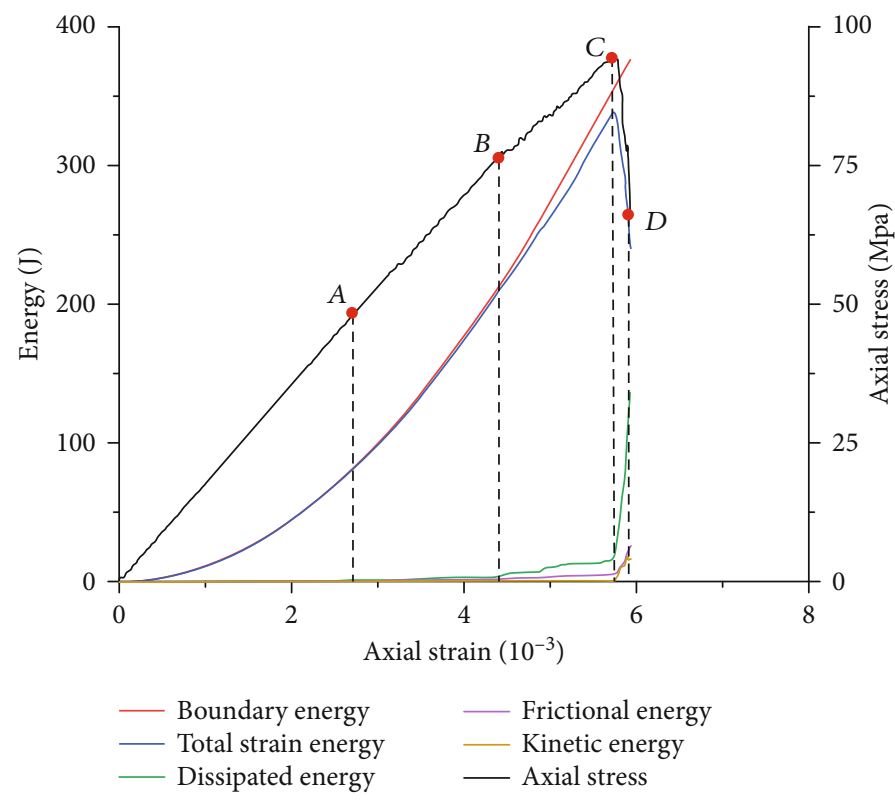

FIGURE 11: Relationship between energy and stress-strain of numerical model $\left(\alpha=45^{\circ}, \beta=60^{\circ}\right)$.

decreased or $\alpha$ increased, the projection of the fissure length in the direction perpendicular to the loading direction gradually becomes shorter, leading to the gradual reduction of the axial closure effect of the fissure under the axial load, and the effective bearing area of the rock actually bearing the load gradually increased, which caused that the strength and the stiffness gradually increased [25].

3.2. Crack Initiation Stress and Damage Stress. The crack initiation stress and damage stress of rock are of great significance for understanding the progressive failure process of rock and establishing its brittle failure mechanism, initiation strength, and long-term strength criterion [31]. Through the method of monitoring microcracks, taking the intact numer- ical model as an example, Figure 9 shows the change curve of the microcrack number in the intact numerical model. The axial stress corresponding to the crack initiation point was taken as the initiation stress $\left(\sigma_{\mathrm{ci}}\right)$, and the axial stress corresponding to the rapid crack growth point was taken as the damage stress $\left(\sigma_{\mathrm{cd}}\right)$ [32].

Table 4 showed the initiation stress and damage stress of all numerical models determined by the above method. The following can be seen: (1) Compared with the intact numerical model, the crack initiation stress and damage stress of the numerical models containing X-shaped fissure were significantly reduced, but the level of crack initiation stress (the ratio of the initiation stress to the peak stress $\left.\left(\sigma_{\mathrm{p}}\right)\right)$ and the level of damage stress (the ratio of damage stress to peak 
stress) did not change much. (2) The level of crack initiation stress in all numerical models was between 0.36 and 0.5 , and the level of damage stress was between 0.76 and 0.84 . Studies [33] have shown that the crack initiation stress of brittle rocks is about 0.25 to 0.5 times the peak stress, and the damage stress is about 0.7 to 0.85 times the peak stress.

Figure 10 shows the curves of the crack initiation stress and damage stress with $\alpha$ and $\beta$. From Figure 10(a), the following can be seen: (1) With the increase of $\beta$, both the crack initiation stress and the damage stress decreased first, then increased, and then decreased, which was consistent with the peak strength. When $\beta=45^{\circ}$, both the crack initiation stress and the damage stress reached the minimum value. (2) With the increase of $\beta$, the level of crack initiation stress and the level of damage stress had no obvious changes, which were between 0.4 and 0.5 and between 0.76 and 0.82 , respectively. When $\beta=45^{\circ}$, the level of crack initiation stress reached the minimum value of 0.4 , and at this time, cracks were most prone to initiation.

From Figure 10(b), the following can be seen: (1) With the increase of $\alpha$, the crack initiation stress and damage stress increased as a whole, which was consistent with the peak strength. (2) With the increase of $\alpha$, the level of crack initiation stress and the level of damage stress had no obvious changes, which were between 0.36 and 0.48 and between 0.80 and 0.84 , respectively. When $\alpha=30^{\circ}$, the level of crack initiation stress reached the minimum value of 0.36 , and at this time, cracks were most prone to initiation.

In comparison, with the changes of $\alpha$ and $\beta$, the range of the level of damage stress was smaller than the level of crack initiation stress, indicating that $\alpha$ and $\beta$ had a greater impact on the level of crack initiation stress than on the level of damage stress.

3.3. Law of Energy Evolution. The essence of rock failure is a state instability phenomenon driven by energy [34], and the study of energy from the perspective of mesomechanics is more in line with actual energy changes. In PFC simulation, the sum of particle bonding energy and strain energy is recorded as total strain energy, and the difference between boundary energy and total strain energy is recorded as dissipation energy [35]. Due to space limitations, the energy evolution law during the loading process was analyzed by taking the numerical model of $\alpha=45^{\circ}$ and $\beta=60^{\circ}$ as an example, as shown in Figure 11, and other numerical models had similar laws.

From Figure 11, the following can be seen: (1) At the initial stage of loading (from point $O$ to point $A$, which was the crack initiation stress point), there were no microcracks, and the boundary energy and the total strain energy increased nonlinearly and basically coincide, indicating that the input boundary energy was all converted into total strain energy, and the dissipation energy, kinetic energy, and friction energy were almost zero. (2) At the linear elastic stage of loading (from point $A$ to point $B$, which was the damage stress point), the microcracks initiated and growed steadily. The growth rate of the boundary energy and the total strain energy gradually increased, and the dissipated energy and the friction energy increased slowly. At point $B$, there was a
TABLE 5: Energy indexes in the peak stress of numerical models.

\begin{tabular}{lcccc}
\hline $\begin{array}{l}\alpha \\
\left({ }^{\circ}\right)\end{array}$ & $\begin{array}{c}\beta \\
\left.{ }^{\circ}\right)\end{array}$ & $\begin{array}{c}\text { Boundary } \\
\text { energy }(\mathrm{J})\end{array}$ & $\begin{array}{c}\text { Total strain } \\
\text { energy }(\mathrm{J})\end{array}$ & $\begin{array}{c}\text { Dissipated } \\
\text { energy }(\mathrm{J})\end{array}$ \\
\hline \multicolumn{2}{l}{ Intact } & 1070.8 & 1035.0 & 35.7 \\
45 & 15 & 439.8 & 418.9 & 20.9 \\
45 & 30 & 402.1 & 386.7 & 15.4 \\
45 & 45 & 325.9 & 308.2 & 17.7 \\
45 & 60 & 356.2 & 338.3 & 17.9 \\
45 & 75 & 383.5 & 360.5 & 23.0 \\
45 & 90 & 303.4 & 284.6 & 18.8 \\
0 & 60 & 371.4 & 332.6 & 38.7 \\
15 & 60 & 332.8 & 301.8 & 30.9 \\
30 & 60 & 364.3 & 342.0 & 22.3 \\
60 & 60 & 391.9 & 373.6 & 18.2 \\
75 & 60 & 373.3 & 363.0 & 10.3 \\
90 & 60 & 605.5 & 567.9 & 37.6 \\
\hline
\end{tabular}

small separation between the boundary energy and the total strain energy curve, and the strain energy stored in contact during the crack propagation process was gradually transformed into dissipated energy. (3) At the plastic yielding stage of loading (from point $B$ to point $C$, which was the peak stress point), the microcracks expand unsteadily, and the boundary energy and the total strain energy curve gradually separated. The total strain energy reached the peak at point $C$, and the growth of dissipation energy gradually increased. (4) After the peak stress (from point $C$ to point $D$ ), the boundary energy continued to increase, the stored total strain energy was rapidly released, and the dissipation energy increased sharply until the model was broken. During the entire deformation and failure process, the boundary energy keeps increasing, the total strain energy first increased and then decreased sharply, and the dissipation energy increased slowly and then increased sharply.

Table 5 shows the energy index of all numerical models at the peak stress. From Table 5, the following can be seen: (1) The total strain energy of all numerical models accounted for a large proportion of the boundary energy at the peak point, indicating that the input energy before the peak stress was mainly stored in the rock in the form of strain energy. (2) Compared with the intact numerical model, the boundary energy, total strain energy, and dissipation energy of the numerical models containing X-shaped fissure were significantly reduced, and the largest decline reached $71.7 \%$, $72.5 \%$, and $71.1 \%$, respectively. It showed that the X-shaped fissure had obvious energy weakening effect on the rock. The total strain energy at the peak stress represents the energy storage limit of the rock and reflects the ability of the rock to resist damage, so the rock containing fissure was more likely to be damaged.

Figure 12 shows the curves of the energy indexes at peak stress with $\alpha$ and $\beta$. The following can be seen: (1) With the increase of $\beta$, the boundary energy and total strain energy showed a decreasing trend as a whole. Specifically, it first decreased, then increased and then decreased, which was 


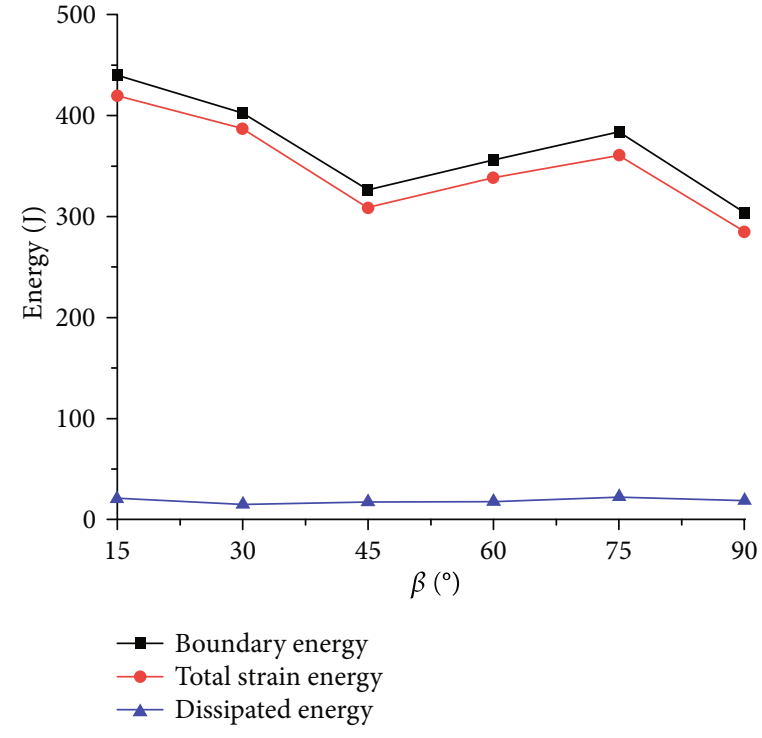

(a) $\alpha=45^{\circ}$

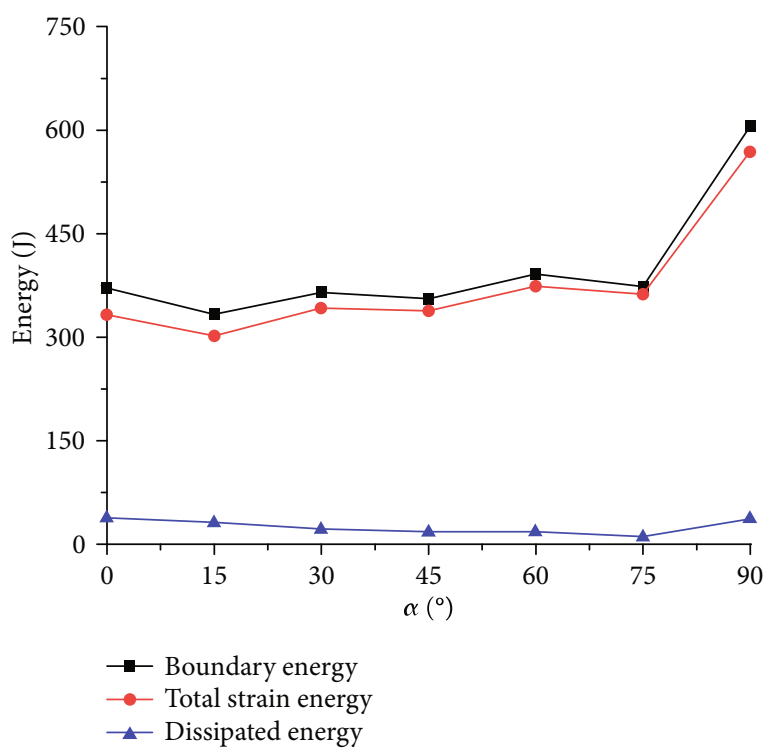

(b) $\beta=60^{\circ}$

FIGURE 12: Change curves of energy indexes of numerical models containing X-shaped fissure in the peak stress.

consistent with the changing law of peak stress in Figure 8(a). (2) With the increase of $\alpha$, the boundary energy and the total strain energy showed an overall increasing trend, which was consistent with the change law of the peak stress in Figure 8(b).

3.4. Crack Propagation Process and Failure Mode. Due to space limitations, the crack propagation process during the loading process was analyzed by taking the numerical model of $\alpha=45^{\circ}$ and $\beta=60^{\circ}$ as an example, as shown in Figure 13. Figures 14 and 15, respectively, show the failure modes of numerical models with different $\alpha$ and $\beta$. The red and black in Figures 13 and 14 represented tensile microcracks and shear microcracks, respectively, and the marked numbers indicated the sequence of macrocracks.

From Figure 13, it can be seen that when the load reached a certain stress level, the model first initiated wing cracks $1^{\mathrm{a}}$ and $1^{\mathrm{b}}$ at the tip of fissure (2) along the extension direction of fissure (2) at an inclination angle of $30^{\circ}$, which was the crack initiation angle [36]. Continuing to load, the wing cracks $1^{\mathrm{a}}$ and $1^{\mathrm{b}}$ propagated to the upper and lower ends of the model along the loading direction, and macrocracks 2 , 3 , and 4 were generated at the tip of fissure (1), which eventually led to the overall failure of the model.

From Figure 14, the following can be seen: (1) Wing cracks $1^{\mathrm{a}}$ and $1^{\mathrm{b}}$ were generated at the two tips of fissure (2). When $\beta=15^{\circ}$, the crack initiation angle was $90^{\circ}$, and when $\beta=90^{\circ}$, the crack initiation angle was $0^{\circ}$. Moreover, with the increase of $\beta$, the crack initiation angle decreased. (2) Macrocrack 2 was produced at the two tips of fissure (1). When $\beta=15^{\circ}$ and $60^{\circ}$, macrocrack 2 was produced at the left tip of fissure (1), and when $\beta=30^{\circ}, 45^{\circ}, 75^{\circ}$, and $90^{\circ}$, macrocracks were generated at the right tip of fissure (1). (3) Macrocracks 3 and 4 were both produced at the two tips of fissure (1) or at the ends of existing macrocracks. (4) When $\beta=15^{\circ}, 30^{\circ}$, $60^{\circ}$, and $75^{\circ}$, the four tips of the X-shaped fissure all had macrocracks and the distribution of microcracks was relatively dispersed, while when $\beta=45^{\circ}$ and $90^{\circ}$, only three tips had macrocracks and microcracks were concentrated at the fissure tips. Since the stress concentration of the former was not as high as that of the latter, the latter will fail at a lower stress level, which was also the reason why the peak strength of the model was small at $\beta=45^{\circ}$ and $90^{\circ}$.

From Figure 15, the following can be seen: (1) Except for $\alpha=0^{\circ}$ and $90^{\circ}$, the numerical models first initiated wing cracks $1^{\mathrm{a}}$ and $1^{\mathrm{b}}$ at the two tips of fissure (2). When $\alpha=0^{\circ}$, the crack initiation angle was $90^{\circ}$; when $\alpha=90^{\circ}$, the crack initiation angle was $67^{\circ}$; and when $\alpha=60^{\circ}$, the crack initiation reached the minimum value of $0^{\circ}$. Moreover, with the increase of $\alpha$, the crack initiation angle first decreased and then increased. (2) Macrocracks 2, 3, and 4 were all generated at the tips of fissure (1) and fissure (2) or at the end of the macrocracks that had been generated. (3) When $\alpha=0^{\circ}$ and $15^{\circ}$, cracks were formed at the tips of fissure (1) and fissure (2), so the peak strength was small. When $\alpha=90^{\circ}$, the four tips of the X-shaped fissure all had macrocracks and the distribution of microcracks was relatively scattered, so the peak strength was large.

From Figures 14 and 15, the following can be seen: (1) Tensile microcracks were the main cracks in the numerical models, and shear microcracks were almost rare. However, there were no microcracks within a certain range of the $\mathrm{X}$ shaped fissure center. (2) The failure mode was mainly split along the axial direction, and the failure surface started from the tips of the fissure and extended to both ends of the numerical models.

In summary, with the changes of $\alpha$ and $\beta$, the numerical models first initiated wing cracks $1^{\mathrm{a}}$ and $1^{\mathrm{b}}$ at the two tips of fissure (2) with a larger dip, and the crack initiation angle decreased with the increase of the inclination angle of fissure 


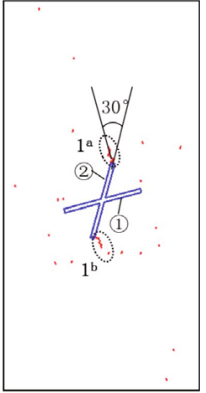

(a) $\sigma=56.3 \mathrm{MPa}, \varepsilon=3.3 \times 10^{-3}$

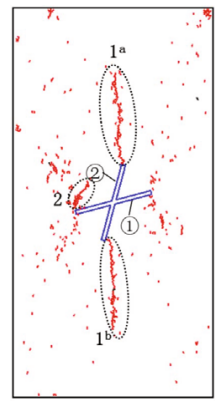

(d) $\sigma=94.5 \mathrm{MPa}, \varepsilon=5.6 \times 10^{-3}$

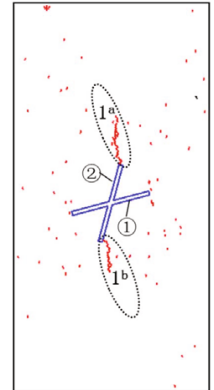

(b) $\sigma=75.8 \mathrm{MPa}, \varepsilon=4.4 \times 10^{-3}$

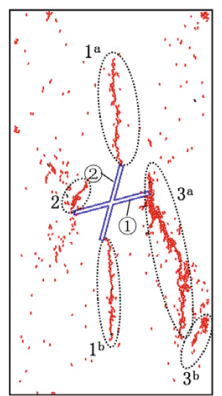

(e) $\sigma=88.4 \mathrm{MPa}, \varepsilon=5.8 \times 10^{-3}$

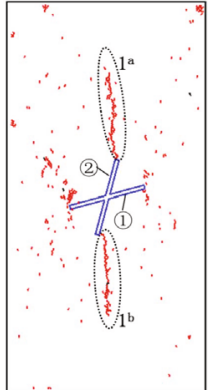

(c) $\sigma=84.8 \mathrm{MPa}, \varepsilon=5.2 \times 10^{-3}$

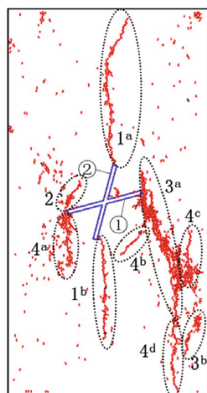

(f) $\sigma=66.6 \mathrm{MPa}, \varepsilon=6.0 \times 10^{-3}$

FIGURE 13: Crack propagation process during the loading process of the numerical model containing X-shaped fissure $\left(\alpha=45^{\circ}, \beta=60^{\circ}\right)$. $($ Red represents tensile microcracks. Black represents shear microcracks. Numbers indicate the order of macrocrack generation. The angle value indicates the crack initiation angle).

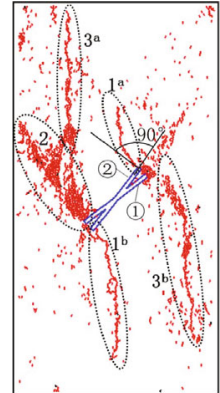

(a) $\beta=15^{\circ}$

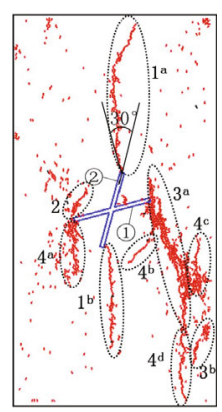

(d) $\beta=60^{\circ}$

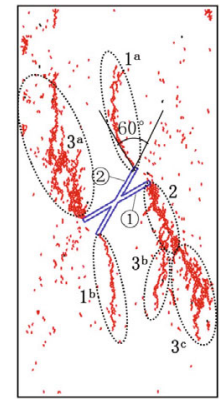

(b) $\beta=30^{\circ}$

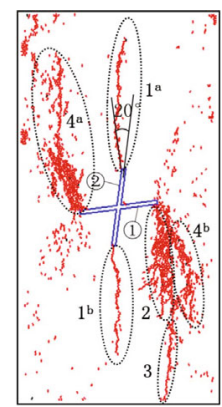

(e) $\beta=75^{\circ}$

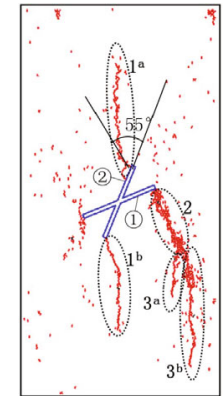

(c) $\beta=45^{\circ}$

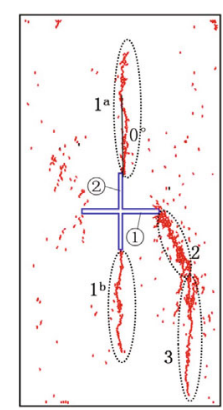

(f) $\beta=90^{\circ}$
FIGURE 14: Failure modes of numerical models with different values of $\beta\left(\alpha=45^{\circ}\right)$. (Red represents tensile microcracks. Black represents shear microcracks. Numbers indicate the order of macrocrack generation. The angle values indicate the crack initiation angle).
(2). From the theory of crack initiation, the relationship between the crack initiation angle of $\theta_{0}$ of a single-opening fissure tip and the inclination angle of $\alpha$ under uniaxial compression is as follows [36]:

$$
\theta_{0}=2 \arctan \frac{1+\sqrt{1+8(\sin 2 \alpha /(1+\cos 2 \alpha))^{2}}}{4(\sin 2 \alpha /(1+\cos 2 \alpha))}
$$

The above formula shows that the crack initiation angle of $\theta_{0}$ decreases with the increase of the inclination angle of $\alpha$, which was consistent with the conclusion of this paper.

\section{Heterogeneity Analysis}

In order to evaluate the influence of the heterogeneity of the mechanical parameters on the macroscopic mechanical properties and failure modes of the rock containing Xshaped fissures under uniaxial compression, the numerical model of $\alpha=45^{\circ}, \beta=60^{\circ}$ was taken as an example, and the homogeneity factor of $m$ was $1,2,3,5,10,20,30$, and 40 , respectively. Figure 16 shows the relationship between the stress-strain curves and the macroscopic mechanical parameters of the numerical models under different homogeneity factors of $m$.

Figure 16 shows the following: (1) When the homogeneity factor of $m$ increased from 1 to 40 , the uniaxial compressive strength and elastic modulus increased from $55.6 \mathrm{MPa}$ and $15.7 \mathrm{GPa}$ to $103.3 \mathrm{MPa}$ and $18.0 \mathrm{GPa}$, respectively, and increased by $85.8 \%$ and $14.6 \%$, respectively. It can be seen that the heterogeneity of mechanical parameters had an impact on 


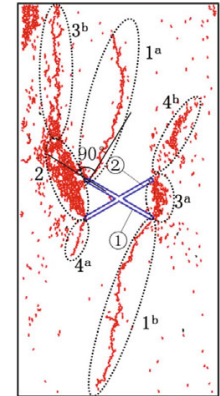

(a) $\alpha=0^{\circ}$

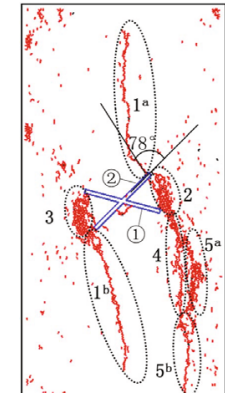

(b) $\alpha=15^{\circ}$

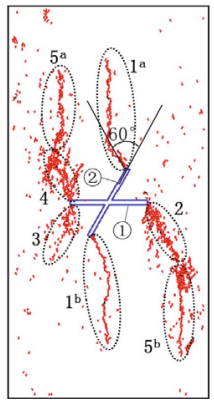

(c) $\alpha=30^{\circ}$

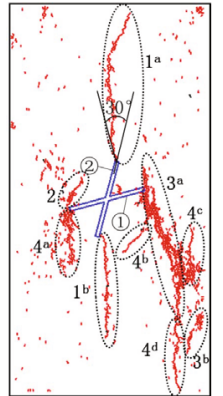

(d) $\alpha=45^{\circ}$

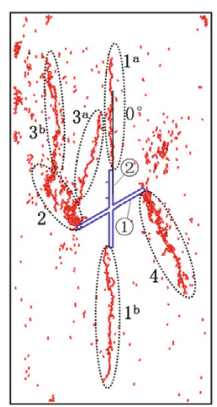

(e) $\alpha=60^{\circ}$

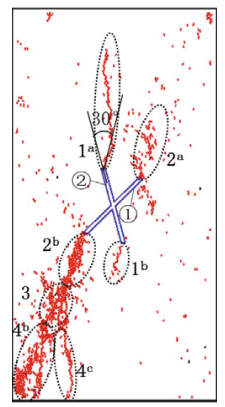

(f) $\alpha=75^{\circ}$

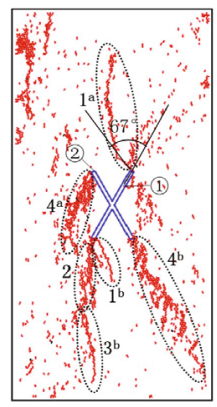

(g) $\alpha=90^{\circ}$

FIGURE 15: Failure modes of numerical models with different values of $\alpha\left(\beta=60^{\circ}\right)$. (Red represents tensile microcracks. Black represents shear microcracks. Numbers indicate the order of macrocrack generation. The angle values indicate the crack initiation angle).

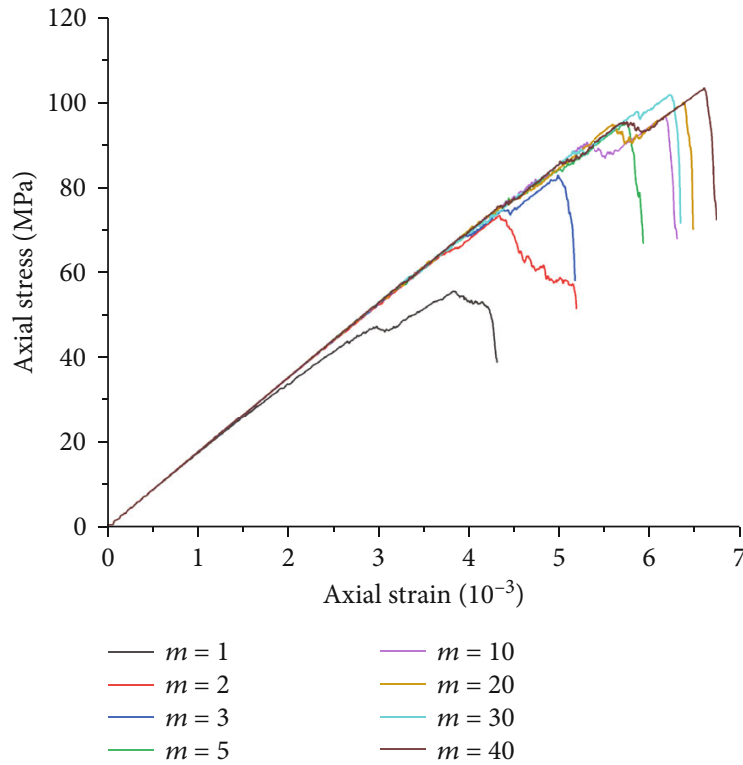

(a) The stress-strain curves

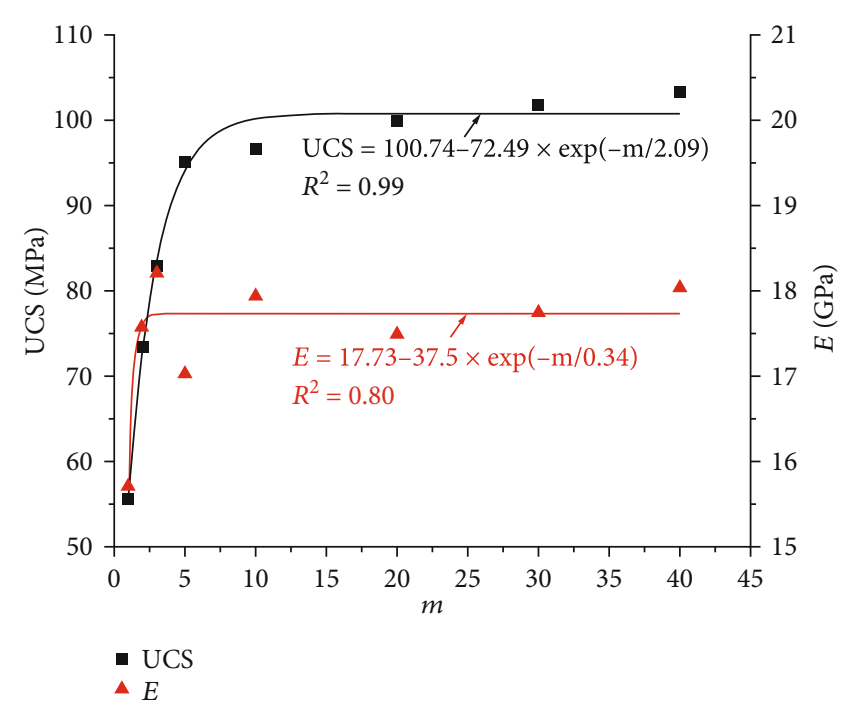

(b) The uniaxial compressive strength and elastic modulus

FIGURE 16: Relationship between macromechanical properties and homogeneity factor of $m$.

the uniaxial compressive strength and elastic modulus, and the influence on the uniaxial compressive strength was obviously greater than the elastic modulus. The reason for this phenomenon was that when the homogeneity factor was large, the strength of the mesoelement was relatively uniform, all the elements shared the external load, and the bearing capacity was large [20]. (2) When the homogeneity factor of $m$ increased from 1 to 10 , the uniaxial compressive strength and elastic modulus increased rapidly; while when the homogeneity factor of $m$ increased from 10 to 40, the uniaxial compressive strength and elastic modulus increased slowly. (3) The relationship of uniaxial compressive strength and elastic 


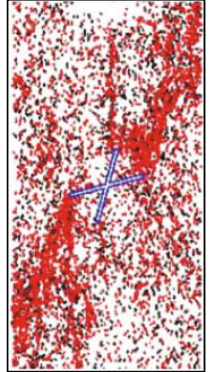

(a) $m=1$

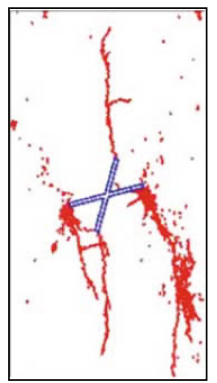

(e) $m=10$

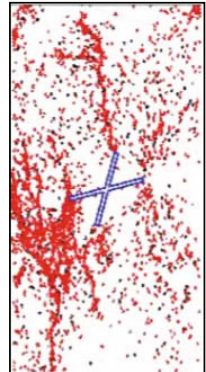

(b) $m=2$

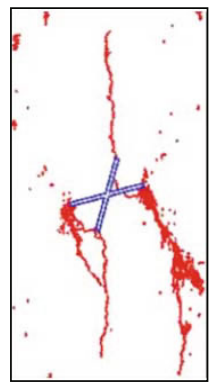

(f) $m=20$

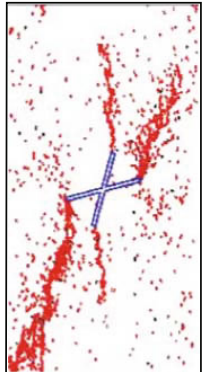

(c) $m=3$

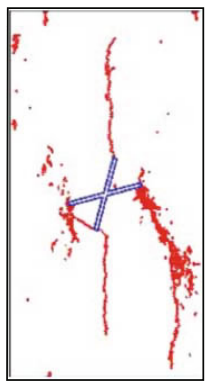

(g) $m=30$

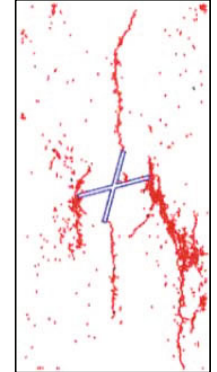

(d) $m=5$

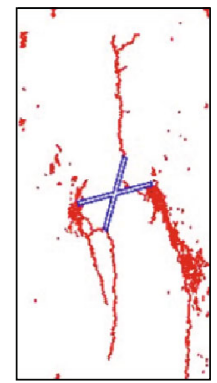

(h) $m=40$

FIGURE 17: Failure modes of numerical models containing X-shaped fissure with different homogeneity factor values of $m$. (Red represents tensile microcracks. Black represents shear microcracks).

modulus with the homogeneity factor of $m$ conformed to the exponential function relationship $\left(R^{2}\right.$ was 0.99 and 0.80 , respectively). These conclusions were consistent with the numerical simulation results of other scholars [37].

Figure 17 shows the failure modes of numerical models containing X-shaped fissure under different homogeneity factors of $m$. The red and black in the figure represented tensile microcracks and shear microcracks, respectively. From Figure 17, it can be seen that the heterogeneity of mechanical parameters had an obvious impact on the failure mode. When the homogeneity factor of $m$ was small, the distribution of microcracks was relatively scattered, while when the homogeneity factor of $m$ was large, the microcracks were mainly distributed in the tip of the X-shaped fissures. These conclusions were consistent with the numerical simulation results of other scholars [29].

\section{Conclusion}

In this paper, the particle flow program $\mathrm{PFC}^{2 \mathrm{D}}$ was used to study the influence of X-shaped fissure and heterogeneity of mechanical parameters on the mechanical behavior of rock under uniaxial compression. The following conclusions were drawn:

(1) Compared with intact rock, the X-shaped fissure not only weakened the brittleness of the rock but also deteriorated the mechanical properties. The deterioration of the peak strength was obviously greater than the elastic modulus. Moreover, the peak strength and elastic modulus generally decreased as $\beta$ increases and increased as $\alpha$ increases
(2) Compared with the intact numerical model, the initiation stress and damage stress of the models containing X-shaped fissure were significantly reduced, but the crack initiation stress level and damage stress level did not change much. Moreover, the change of the crack initiation stress and damage stress with $\alpha$ and $\beta$ was consistent with peak strength

(3) Compared with the numerical intact model, the Xshaped fissure had obvious energy weakening effect on the rock, so the rock containing fissure was more likely to be damaged. The change of boundary energy and total strain energy with $\alpha$ and $\beta$ at peak stress was consistent with peak strength

(4) The fracture was dominated by tensile microcracks, and no microcracks were generated in a certain range of the X-shaped fissure center. The failure mode was mainly split along the axial direction, and the failure surface started from the tips of the fissure and extended to both ends of the model

(5) Regardless of the changes of $\alpha$ and $\beta$, the models all firstly initiated wing cracks $1^{\mathrm{a}}$ and $1^{\mathrm{b}}$ at the two tips of fissure (2) with a larger dip, and the crack initiation angle decreased with the increase of the inclination angle of fissure (2)

(6) The uniaxial compressive strength and elastic modulus increased exponentially with the increase of the homogeneity factor of $m$. When the homogeneity factor of $m$ was small, the microcracks were more evenly distributed in the model, and when the homogeneity factor of $m$ was large, the microcracks mainly concentrated at the tips of the fissure 


\section{Data Availability}

The data used to support the findings of this study are included within the article.

\section{Conflicts of Interest}

The authors declare that there are no conflicts of interest regarding the publication of this paper.

\section{Acknowledgments}

The research was financially supported by the National Key R\&D Program of China (Grant No. 2016YFC0401802), State Key Program of National Natural Science of China (Grant No. 51539002), and National Natural Science Foundation of China (Grant No. 51779249).

\section{References}

[1] Y. L. Wang, J. X. Tang, Z. Y. Dai, and T. Yi, "Experimental study on mechanical properties and failure modes of lowstrength rock samples containing different fissures under uniaxial compression," Engineering Fracture Mechanics, vol. 197, pp. 1-20, 2018.

[2] S. Q. Yang, H. W. Jing, and T. Xu, "Mechanical behavior and failure analysis of brittle sandstone specimens containing combined flaws under uniaxial compression," Journal of Central South University, vol. 21, no. 5, pp. 2059-2073, 2014.

[3] L. N. Y. Wong and H. H. Einstein, "Systematic evaluation of cracking behavior in specimens containing single flaws under uniaxial compression," International Journal of Rock Mechanics \& Mining Sciences, vol. 46, no. 2, pp. 239-249, 2009.

[4] S. Q. Yang, X. R. Liu, and H. W. Jing, "Experimental investigation on fracture coalescence behavior of red sandstone containing two unparallel fissures under uniaxial compression," International Journal of Rock Mechanics and Mining Sciences, vol. 63, pp. 82-92, 2013.

[5] J. Lu, G. Z. Yin, D. M. Zhang, X. Li, G. Huang, and H. Gao, "Mechanical properties and failure mode of sandstone specimen with a prefabricated borehole under true triaxial stress condition," Geomechanics for Energy and the Environment, vol. 25, article 100207, 2020.

[6] Y. X. Wang, H. Zhang, H. Lin, Y. Zhao, and Y. Liu, "Fracture behaviour of central-flawed rock plate under uniaxial compression," Theoretical and Applied Fracture Mechanics, vol. 106, p. 102503, 2020.

[7] Y. L. Zhao, L. Y. Zhang, W. J. Wang, C. Pu, W. Wan, and J. Tang, "Cracking and stress-strain behavior of rock-like material containing two flaws under uniaxial compression," Rock Mechanics and Rock Engineering, vol. 49, no. 7, pp. 2665-2687, 2016.

[8] Q. H. Wu, L. Weng, Y. Zhao, F. Zhao, W. Peng, and S. Zhang, "Deformation and cracking characteristics of ring-shaped granite with inclusion under diametrical compression," Arabian Journal of Geosciences, vol. 13, no. 14, p. 681, 2020.

[9] L. Weng, X. Li, A. Taheri, Q. Wu, and X. Xie, "Fracture evolution around a cavity in brittle rock under uniaxial compression and coupled static-dynamic loads," Rock Mechanics and Rock Engineering, vol. 51, no. 2, pp. 531-545, 2018.
[10] Q. H. Wu, X. Li, L. Weng, Q. Li, Y. Zhu, and R. Luo, "Experimental investigation of the dynamic response of prestressed rockbolt by using an SHPB-based rockbolt test system," Tunnelling and Underground Space Technology, vol. 93, article 103088, 2019.

[11] L. Weng, Z. Wu, and Q. Liu, "Influence of heating/cooling cycles on the micro/macrocracking characteristics of Rucheng granite under unconfined compression," Bulletin of Engineering Geology and the Environment, vol. 79, no. 3, pp. 12891309, 2020.

[12] Q. H. Wu, L. Chen, B. T. Shen, B. Dlamini, S. Q. Li, and Y. J. $\mathrm{Zhu}$, "Experimental investigation on rockbolt performance under the tension load," Rock Mechanics and Rock Engineering, vol. 52, no. 11, pp. 4605-4618, 2019.

[13] Y. X. Wang, H. Zhang, H. Lin, Y. Zhao, X. Li, and Y. Liu, "Mechanical behavior and failure analysis of fracture-filled gneissic granite," Theoretical and Applied Fracture Mechanics, vol. 108, article 102674, 2020.

[14] Y. L. Zhao, L. Zhang, W. Wang, Q. Liu, L. Tang, and G. Cheng, "Experimental study on shear behavior and a revised shear strength model for infilled rock joints," International Journal of Geomechanics, vol. 20, article 04020141, no. 9, 2020.

[15] C. L. Wang, Y. Zhao, Y. L. Zhao, and W. Wan, "Study on the interaction of collinear cracks and wing cracks and cracking behavior of rock under uniaxial compression," Advances in Civil Engineering, vol. 2018, Article ID 5459307, 10 pages, 2018.

[16] X. R. Liu, S. Q. Yang, Y. H. Huang, and J. L. Cheng, "Experimental study on the strength and fracture mechanism of sandstone containing elliptical holes and fissures under uniaxial compression," Engineering Fracture Mechanics, vol. 205, pp. 205-217, 2019.

[17] J. Y. Wu, M. M. Feng, B. Y. Yu, and G. Han, "The length of preexisting fissures effects on the mechanical properties of cracked red sandstone and strength design in engineering," Ultrasonics, vol. 82, pp. 188-199, 2018.

[18] Q. Q. Dong, H. J. Wei, and G. W. Ma, "Failure mechanism of S-shaped fissure in brittle materials under uniaxial tension: experimental and numerical analyses," International Journal of Solids and Structures, vol. 191-192, pp. 486-496, 2020.

[19] G. W. Ma, Q. Q. Dong, L. F. Fan, and J. W. Gao, “An investigation of non-straight fissures cracking under uniaxial compression," Engineering Fracture Mechanics, vol. 191, pp. 300310, 2018.

[20] S. Q. Yang, Z. Yang, P. C. Zhang, and W. L. Tian, "Experiment and peridynamic simulation on cracking behavior of red sandstone containing a single non-straight fissure under uniaxial compression," Theoretical and Applied Fracture Mechanics, vol. 108, no. 102637, p. 102637, 2020.

[21] S. Q. Yang, W. L. Tian, Y. H. Huang, Z. G. Ma, L. F. Fan, and Z. J. Wu, "Experimental and discrete element modeling on cracking behavior of sandstone containing a single oval flaw under uniaxial compression," Engineering Fracture Mechanics, vol. 194, pp. 154-174, 2018.

[22] L. Y. Chen and J. J. Liu, "Numerical analysis on the crack propagation and failure characteristics of rocks with double fissures under the uniaxial compression," Petroleum, vol. 1, no. 4, pp. 373-381, 2015.

[23] S. Q. Yang, Y. H. Huang, H. W. Jing, and X. R. Liu, "Discrete element modeling on fracture coalescence behavior of red sandstone containing two unparallel fissures under uniaxial compression," Engineering Geology, vol. 178, pp. 28-48, 2014. 
[24] D. M. Huang, X. K. Chang, Y. L. Tan, J. Zhou, and Y. Yin, "Numerical study of the mechanical and acoustic emissions characteristics of red sandstone under different double fracture conditions," Symmetry, vol. 11, no. 6, pp. 772-788, 2019.

[25] G. L. Wang, L. Zhang, M. Xu, Z. Y. Liang, and B. L. Ran, "Energy damage evolution mechanism of non-across jointed rock mass under uniaxial compression," Chinese Journal of Geotechnical Engineering, vol. 41, no. 4, pp. 639-647, 2019.

[26] Itasca Consulting Group Inc, PFC, Version 5.0, Minneapolis, Itasca Consulting Group Inc, 2014.

[27] P. A. Cundall and O. D. L. Strack, "A discrete numerical model for granular assemblies,” Géotechnique, vol. 29, no. 1, pp. 4765, 1979.

[28] H. M. Shen, Q. Li, X. Y. Li, and J. L. Ma, "Laboratory experiment and numerical simulation on brittle failure characteristics of Longmaxi formation shale in Southern Sichuan under different stress conditions," Rock and Soil Mechanics, vol. 39, no. S2, pp. 254-262, 2018.

[29] C. A. Tang, L. G. Tham, S. H. Wang, H. Liu, and W. H. Li, “A numerical study of the influence of heterogeneity on the strength characterization of rock under uniaxial tension," Mechanics of Materials, vol. 39, no. 4, pp. 326-339, 2007.

[30] C. A. Tang, H. Liu, P. K. K. Lee, Y. Tsui, and L. G. Tham, "Numerical studies of the influence of microstructure on rock failure in uniaxial compression-part I: effect of heterogeneity," International Journal of Rock Mechanics and Mining Sciences, vol. 37, no. 4, pp. 555-569, 2000.

[31] C. D. Martin and N. A. Chandler, "The progressive fracture of Lac du Bonnet granite," International Journal of Rock Mechanics and Mining Sciences \& Geomechanics Abstracts, vol. 31, no. 6, pp. 643-659, 1994.

[32] F. Pelli, P. K. Kaiser, and N. R. Morgenstern, “An interpretation of ground movements recorded during construction of the Donkin-Morien tunnel," Canadian Geotechnical Journal, vol. 28, no. 2, pp. 239-254, 1991.

[33] M. S. Diederichs, A. Coulson, V. Falmagne, M. Rizkalla, and B. Simser, "Application of rock damage limits to pillar analysis at Brunswick Mine," in Proceedings of the North American Rock Mechanics Conference. Toronto: University of Toronto Press, pp. 1325-1332, Toronto, 2002.

[34] G. H. Liu, Z. T. Liu, J. J. Feng, Z. Song, and Z. Liu, "Experimental research on the ultrasonic attenuation mechanism of coal," Journal of Geophysics and Engineering, vol. 14, no. 3, pp. 502512, 2017.

[35] Y. Luo, G. Wang, X. P. Li et al., "Analysis of energy dissipation and crack evolution law of sandstone under impact load," International Journal of Rock Mechanics and Mining Sciences, vol. 132, p. 104359, 2020.

[36] H. Lin, H. T. Yang, Y. X. Wang, Y. Zhao, and R. Cao, "Determination of the stress field and crack initiation angle of an open flaw tip under uniaxial compression," Theoretical and Applied Fracture Mechanics, vol. 104, article 102358, 2019.

[37] H. Y. Liu, M. Roquete, S. Q. Kou, and P. A. Lindqvist, "Characterization of rock heterogeneity and numerical verification," Engineering Geology, vol. 72, no. 1-2, pp. 89-119, 2004. 